\title{
Match Making, Structural Holes, and Arranged Marriages: The Process of Small Multinational Enterprises International Alliance Formation
}

\author{
Clifford Wymbs \\ Zicklin School of Business, Baruch College, City University of New York, USA
}

Copyright $(2016$ by authors, all rights reserved. Authors agree that this article remains permanently open access under the terms of the Creative Commons Attribution License 4.0 International License

\begin{abstract}
The analysis found that to share in the gains of a globalizing economy, smaller multinational enterprises find surrogates outside their firm, third party enablers, to help bridge informational structural holes and build multi-nodal social networks that link cross-cultural alliances partners. Using a qualitative case study, propositions for future testing were developed that highlight similarities and differences between large and small firms, the role third parties play with small firms, and how these third-party behaviors co-evolve with the alliance partners. Conceptual and practical issues related to the changing role of third parties are identified and discussed.
\end{abstract}

Keywords Longitudinal Study, Alliances, Social Networks, Third Party Intermediaries

\section{Introduction}

In an era of rapid globalization and collaboration, the small and medium-sized enterprise (SME) alliance topic is crucial because SMEs are the fastest growing business segment and account for the greatest job growth. Yet because of information market failures they have great difficulty in identifying foreign alliance partners to aid in their innovation processes. The Internet has facilitated the search for potential alliance partners; however, few SMEs have the time and/or expertise to translate a search response into a future business partner. SMEs cannot rely on the historical reputation, pre-paid advisors, and financial solidity that large firms often use to identify and target alliance partners. If SMEs are to efficiently participate in rapidly growing inter-country knowledge sharing alliances, they need to invent new processes that mitigate their informational weaknesses and capitalize on their innovative, entrepreneurial strengths. The main body of alliance research that focuses on large multinational enterprises (MNEs) provides limited guidance here.
When to form an inter-firm alliances versus the selection of alternative governance modalities has received extensive research attention (see, e.g., Das and Teng, 2002, Dacin, Reid, \& Ring, 2002); however, the dynamics involved to reach agreements and why some attempts to form alliances succeed or fail, remain as underdeveloped research topics (Arino \& Ring, 2010). Because much of alliance research is based on transaction cost (Hennart, 1988, Chi 1994, Reuer, Koza and Mitchell, 2000) that is static and focuses on when the alliance organization is a more efficient governance mechanism, this research provides little guidance with regard to the way firms reach decisions to pursue an alliance, identify candidate alliance partners, and determine key relational values that are critical in negotiating and decision making. Alliance formation processes involve difficult to model, dynamic interactions and social dimensions not explicitly tied to economics, i.e., bridging structural holes, making distant alliance parties aware of candidate interest and adhering to procedural fairness - making sure partners perceive that the allocation procedures for decision making rights are fair (Arino \& Ring, 2010).

Verbal accounts, similar to the actual ones below, highlight the complexity of organizational processes associated with the creation of both large and small alliances, e.g., "the alliance of the Scottish Royal Bank of Scotland, the Spanish Banco Santander, and the Belgian Fortis bank to buy the Dutch ABN Amro bank was established via the personal contacts of a US investment banker" and "when I was working for a Belgian SME, I recall we had great difficulty finding a reliable alliance partner in Eastern Europe, and it was only after a trusted German business partner established a contact with a Polish firm that we came to an alliance - after years of active searching in the turbulent Eastern European business environment of the early 1990s." However, few have attempted to "open the black box" of organizational processes, the "who", "how", and "why" of individual and collective organized action as it unfolds over time and in context (Doz, 2011). A partial deconstruction of these statements reveals many interesting sub-questions that 
require theoretical attention: Who thought of the alliance idea and did the banker know all the parties or were there a series of contacts? How was it sold to each of them and what criteria were involved in each party's decision process? Why was each of the parties interested and who determined procedural fairness? Insight into these real world business questions and problems can only be obtained through a systematic analysis of the phenomenon in its natural context that explores the relationship among observed participants, and the sequence of steps involved (Doz, 2011).

Specifically, this research addresses the matchmaking and the procedural fairness components of the international alliance problem for SMEs. It focuses on the extremely important social, rather than economic (transaction cost), processes involved. In addition to practical considerations associated with increasing the success of creating alliances for this information starved SME segment, this research also fills several gaps in other related literatures, i.e., the structural holes literature that typically addresses ego networks where individuals bridge holes between other individuals, not persons bridging holes between companies, and the alliance literature that typically assumes that alliance partners establish direct contacts with prospective (foreign) partners and create a dedicated internal alliance function. Also, alliance literature is silent on the process used by firms to create their firm's first alliance, i.e., how firms develop know-how without actual collaborative experience. Thus the topic, "What role do external intermediaries play in establishing and cultivating international alliances among small and medium-sized enterprises?" fits in between, and has potential to contribute to, each of these streams.

\section{Literature Review}

The last two decades have seen an unprecedented, worldwide growth in the number of inter-firm alliances, voluntary arrangements which may or may not be equity-based, (Harrigan, 1985; Contractor \& Lorange, 1988; Gomes-Casseres, 1996; Inkpen \& Beamish, 1997; Dunning \& Wymbs 2003 Beamish, \& Lupton, 2009). Alliances, as an organizational form, are a challenge to study because they are complex in design and can be viewed as incomplete contracts fraught with ambiguity (Anand and Khanna, 2000). However, Kale and Singh (2007), Dyer, Kale \& Singh (2001) and Shee (2006) all indicate that there is an alliance learning process involving first ordering partnering skill and routines to manage different phases in the life cycle of any alliance, i.e., alliance conception and partner selection, alliance negotiation, formulation of the alliance design, post-formulation alliance management, etc. For the most part, the focus of alliance studies has been on large, mature, multinational dyad partnerships; however, recent technological innovation, increased global competition, and the Internet have created fertile ground for SMEs to seek similar international alliance arrangements (Oviatt \& McDougall, 1994)
Gulati (1995) observed that most accounts of alliance formation did not focus on how firms learned about new alliance opportunities and for the ones that did, they wrongly assumed that partnering information was freely available. Beckman, Haunschild, \& Phillips (2004) identified how social networks play a critical role in alliance formation, particularly those created during prior alliances, while Gulati, Lavie, and Singh, (2009) further refined this by differentiating the performance between firms that had general alliance experience versus those that had alliance experience with the same partner. However, most existing social networking studies on joint ventures or alliance formation emphasize the role of entrants and their partners (e.g., Coviello and Munro, 1997, Gemser, Brand, Sorge, 2000), but downplay or not mention at all the role third party intermediaries play in bridging the differences in market knowledge, trust, and psychic distance (e.g., Ellis 2000, Todeva and Knoke, 2005). Coviello \& McAuley, (1999) observed that SME behave differently than their larger counterparts in the analysis of, and interaction with, their environment. SME do not have an extensive alliances portfolio to tap into nor do they have sufficient resources to create dedicated alliance procedures and must look elsewhere to obtain information about potential alliance partners. Ellis (2000) stated that little is known about the ways and the means by which firms come to identify specific exchange partners. Leonidou (2004) found the inability to obtain information about foreign market players as a key impediment to SME international expansion. The resource-constrained SME seeking an international alliance partner appears to be an ideal setting to extend structural hole and alliance research (Gemer, Brand, \& Sorge, 2004).

More formally, the research question is: How do resource-constrained SME leverage dynamic third party relationships to bridge information holes and create cross-cultural alliances? The main contributions of the paper is the "opening the black box" of formative alliance organizational processes, i.e, the "how", "who" and "why" of individual and collective organized action as it unfolds over time in context (Doz, 2011).

\section{Conceptual Foundation}

To guide the discussion, a high level teleological process model is presented that demonstrates how the conceptual pieces of the SME international alliance research puzzle fit together. Teleological theory assumes that the entities are purposeful and adaptive, interactive with one another to construct an envisioned end state, take action to reach it, and monitor their progress (Poole, et al., 2000). Even though teleological theory does not prescribe a necessary sequence of events or specify which trajectory development will follow to achieve the goal, it does recognize that the "organization's environment and its resources of knowledge, time, money, etc. constrain what it can accomplish" (Poole, et al. 2000, 62). The analysis below will show how the goal 
of a successful international alliance is accomplished via a relatively stable sequence of events subject to severe SME information constrains.

The model is composed of three separate constructs, explanatory, mediating, and dependent, that are introduced here and explained in detail in their own sections that follow. The explanatory construct addresses the process involved in how two firms (SMEs or large MNEs) overcome information asymmetries/imperfections, divergent business cultures and different objectives to form an incomplete contract ultimately leading to the discussion of a possible alliance. The main difference between SME international alliances (versus large firms) revolves around how they bridge information gaps. SME often require extra-firm help in this area, a mediation construct, i.e., how and by whom the alliance partners learn about each other and are brought together. The causal scheme depicting the SME mediating construct (relating back to identifying the international alliance partner and forward to the successful alliance) is quite complex and requires detailed data to uncover actual process activities and interactions that lead to the creation of a relational alliance network (Doz, 2011). The "thick tale" i.e., a progressively unfolding story of a multi-actor narrative of the evolving events in a company or a sub-unit, facilitates the building of a logical model. It focuses on how third-party intermediaries (with their personal networks, status of trustworthiness, and socio-political skills) ultimately become the key mediating construct (VanMaanen, 1988). The dependent construct involves the achievement of the goal, a successful alliance partnership between two firms, and the socially constructed next steps of the parties. The resulting model displayed in Figure 1, represents an ecological approach and shows how individual components of the three constructs interact and become an interrelated system (Bergulman, 2011).

\section{Explanatory Construct}

The explanatory construct focuses on the broad processes of overcoming information asymmetries between the alliance parties, taking into account the role of context. Context is extremely important to consider not because it directly causes what happens, but rather because it can certainly determine the consequences (Gaddis, 2005). The explanatory construct helps answer the question: Are there similar broad processes and contexts that apply to formation of both large and small international alliances? Studies have found that large companies have much detailed processes associated with internalizing alliances, e.g., Lotus has its "35 rules of thumb" to mange their alliance processes, while Hewlett-Packard developed 60 different tools and templates and a 300-page manual on alliances (Kale, Dyer \& Singh, 2002).

\section{Conceptual Research Typology}

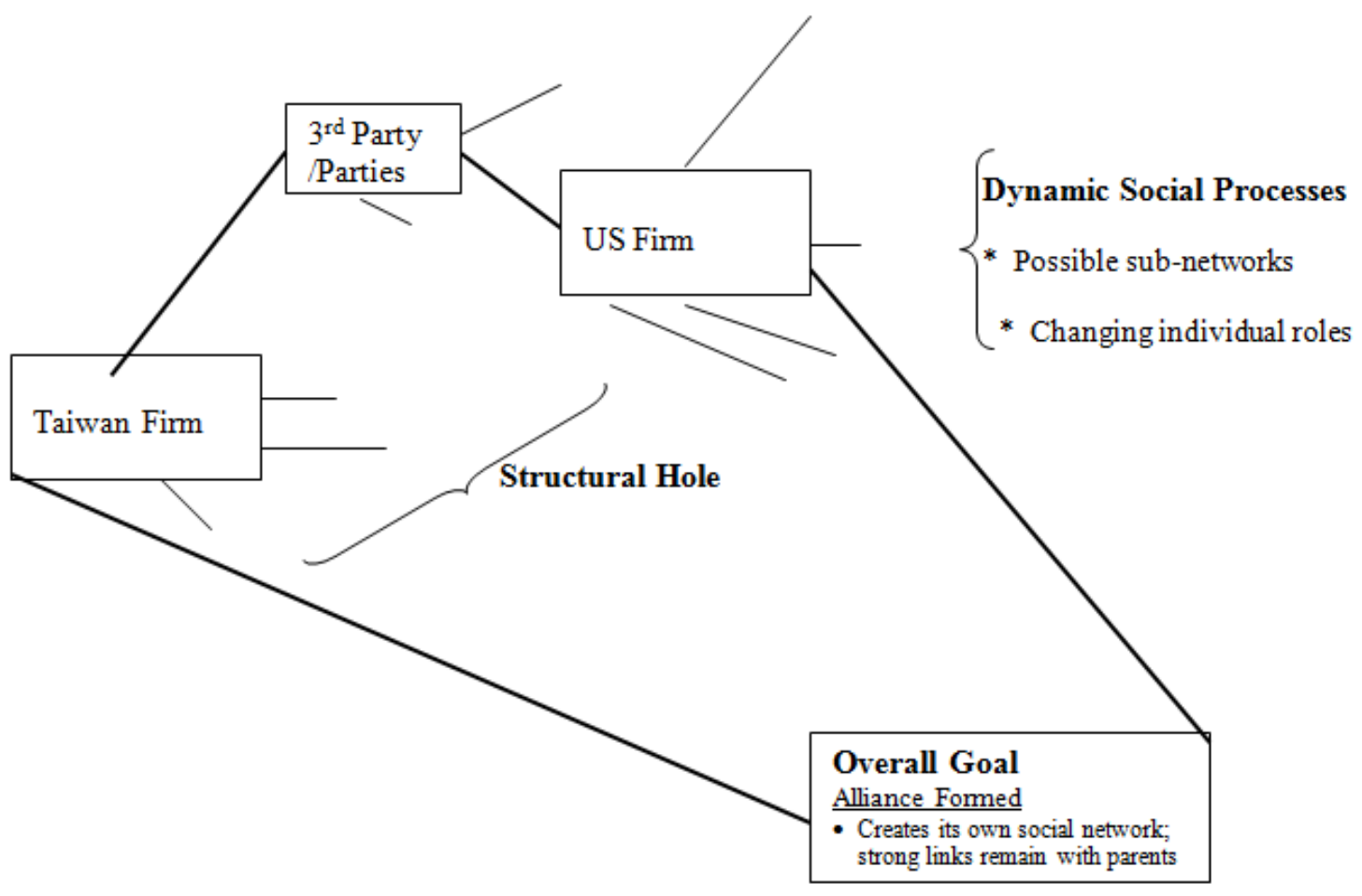

Figure 1. Conceptual Research Typology 
Entrepreneur research indicates that smaller firms' processes are more organic in nature and likely to be relationship rather than rules based; however, the empirical question, "are the broad alliance creation phases the same?" needs further analysis (Kuemmerle, 2004). For large firms, Beamish and Lupton (2009), Shee (2006), and Dyer, Kale \& Singh (2001) grouped alliance lifecycle processes into similar main phases or areas: (1) Business case/needs assessment; (2) Partner Assessment and Selection; (3) Alliance Negotiation and Governance; (4) Alliance management; and (5) Alliance Termination. The above stage/phase processes have not been tested with regard to international SMEs; however, they would seem to provide a base case and guidance to begin the analysis.

\section{Mediating Construct}

Alliance studies in the business environment have almost exclusively focused on dyad relationships; while in sociology the attention and importance of triads goes back to the work of Georg Simmel (Krackhardt, 1999). Simmel (1950) states that each in a dyad knows that he can depend only on the other and on nobody else; this gives the dyad a special consecration. The adding of a third or even a fourth person to the dyad completely changes all relationships, each one now operates as an intermediary between the other two, exhibiting the two fold function of uniting and separating. Discords between two parties which they themselves cannot remedy, are accommodated by the third or absorption in a comprehensive whole. Simmel (1950) also asserts that further expansion to four or more by no means correspondingly modifies the group any further. Using the family analogy, the husband and wife dyad is changed significantly with the addition of the first child, but the second child has much less of an effect.

Only a relatively few management research studies have identified specific, important roles third parties play in alliance transactions, i.e., Finlay \& Coverdill (2000) identified the need for third-party intermediaries in those employment recruiting markets where search costs for identifying potential clients were high, Pollock, Porac \& Wade (2004) found in IPO markets that third-party brokers could facilitate exchange processes when markets were uncertain and social variables such as familiarity provided useful information. In the context of M\&A, Elsbach \& Kramer (2003) discussed the dealmaker prototype to be "concept" people focusing on commercial appeal, knowing the industry lingo, and being charismatic and self-assured in their presentation of concepts. In each of these studies, the third party is depicted as having a single, unchanging, and in most cases, relatively minor role in the evolution of the key alliance events.

Social network theory is an extension of the dyad analysis of Simmel and also affects the mediating construct in alliance formation. Burt (1992; 2000; 2002; 2004), Coleman (1990), Tsai \& Ghoshal (1998) and Gulati (1995) have identified key points associated with social network theory in a business context. They found that: (1) People focus on activities inside their own group, which creates holes in information flows among groups, i.e., structural holes; (2) People whose networks bridge the structural holes between groups have a key advantage. Simmel (1950) found that there are two possible motives for a third party to bridge structural holes: (1) The most citied tertius gaudens type, similar to Burt (2004), has the third party seeking to leverage his position for personal gain by manipulating the relationship between the two disconnected parties; (2) The tertius iungens type, discussed by Obstfeld (2005), has the third party serving as the means to the end for the group, e.g., connecting people in different social networks and/or facilitating new coordination between connected groups. In this way, the bridging third party shares a common goal with at least one of the affected network members and this relationship is more communal than transactional.

Unlike most social network research that treats network structure as immutable and static, the Reed (1997) and the Kilduff \& Tsai (2005) view permits social networks to change over time with micro-level individual processes interacting, affecting, and being affected by, macro organizational processes. Dynamic networks must co-evolve with the environment and often require bridges for emerging informational structural holes. Krackhardt (1999) found that the formation of dynamic networks is often driven by a goal.

Birkinshaw, Brannen, Tung, (2011) highlighted cultural context as another important factor in creating social networks and overcoming information asymmetries and contextual variability. Other studies suggest the importance of cultural attributes, as well as cultural distance between partners, as contextual factors to consider in partner selection, governance mode, IJV management, IJV survival, and sequential buyouts (Shenkar 2004; Adler, 1997; Erramilli, 1996; Weber; Shenkar \& Raveh, 1996). However, cultural context in alliance formation has rarely entered into the equation when studying the alliance process for small firms, even though country context manifested in cultural differences is likely to be more of a problem in small firms than large ones because small firms are likely to have less knowledge about the other firm. Thus, cultural differences could lead to significant structural information holes in negotiations between SMEs and may require third parties to complete the social network and serve as human information/relationship bridges between firms (Folta \& Ferrier, 2000).

\section{Dependent Construct}

The dependent construct is the successful completion of the SME international alliance. Most quantitative studies use some form of profitability as the dependent construct (Kale and Singh, 2007; Anand and Khanna, 2000; Gulati, Lavie, and Singh, 2009; Simonin, 1997) and formally test hypotheses associated with the key explanatory variables. Using qualitative rather than quantitative research techniques, the dependent construct here identifies and describes the actual human interaction processes of achieving the goal and teases out conceptual insights that 
reveal how relationships and reputations become future currencies rather than traditional measures. Narratives are used to show how participants cope and make sense of partner, market, and technological uncertainties and permit new trajectories and attributions to evolve (Pentland, 1999, Wieck, 2007, Birkinshaw, Brannen, Tung, 2011).

\section{Research Setting, Methods and Data Collection and Analysis}

Qualitative approaches, particularly longitudinal case studies, appear particularly appropriate to explore the impact third parties play in the alliance formation process. Pentland (1999) argued that stories help explain and provide meaning to the relationships between events in a process, and sequential patterns are most critical to explanation. With regard to the study's validity, Gibbert, Ruigrok, and Wicki (2008) and Yin (2003) identified relevant procedures associated with construct validity (establishing multiple sources and chains of evidence), internal validity (establishing explanations and causal relations), external validity (establishing the domain where the study can be generalized), and reliability (repeating the case study with the same results). This analysis used these procedures as guides, but could not conform to one of the reliability procedures, i.e., "names - revealing the firms' actual names" because the firms would not permit it.

\section{Research Setting}

A contextualized explanation approach to theorizing was applied to the multiparty, two-level negotiations that created the IJVs described below. Fundamental to this approach are case studies that generate causal explanations that preserve rather than eradicate contextual richness (Welch, et al., 2011). A "real time" approach as employed in these studies is rarely selected because such privileged access to data, particularly in formative stages of alliance formation processes is usually unavailable due to proprietary concerns. Also, real time information is difficult to obtain because researchers may not have enough time to gain entry before things are over and/or partners, lawyers, investment bankers, and others, may not be interested in having an 'outsider' observing the events (Arino \& Ring, 2010). When researchers have an opportunity to gain access to and analyze a phenomenon rarely seen by other researchers, the conditions justify the use of a case study even if the phenomenon is common as opposed to rare or unique (Yin, 2003). As with many case studies, the names of the firms that were studied during negotiation processes have been disguised, as have the names of the individuals that were involved (Arino \& Ring, 2010).

\section{Method}

In general, process theories use a story or a historical narrative to explain the temporal order and sequence in which discrete events occur (Abbott, 1988; Doz, 2011).
Narrative histories of sequences of events are first compiled then pattern-matching methods are employed to derive the underlying generative mechanism. Pettigrew (1990) argues that theoretically sound and practically useful research on change should explore the contexts, content, and process of change together with the interconnections through time. Van De Ven \& Huber (1990) warned, that the sheer labor intensity required to observe an organizational change process over time limits a researcher's capabilities to study more than a few cases at a time.

One variant of process theory is "contextualised explanation." This method of theorising is based on the assertion that case studies can generate causal explanations that preserve rather than eradicate contextual richness (Welch, 2011). Proponents assert that explanatory accounts are necessarily context-bound: as Sayer (1992: 60) has written, "making sense of events requires that we 'contextualize' them in some way." Contextualised explanation is concerned with accounting for why and how events are produced. Understanding how the outcome in a particular case was brought about (e.g., "A led to E through steps B, C, D") entails working backwards from events (cause-of-effects explanations) rather than estimating the net effects of causes (effects-of-causes explanations) (Mahoney \& Goertz, 2006; Welch et al. 2011; Lawson, 2003). Initially, the "dependent construct" $E$, the desire of the firm to secure an alliance partner is identified. Then the "explanatory construct," the typical macro processes that both large and small firms undertake to execute their alliance objective is explored. Because small firms cannot proceed sequentially from A to E, they need extra-firm bridges, a "mediating construct," to navigate the alliance process. This "mediating construct" is deconstructed in detail to highlight the uniqueness of the SME international alliance process associated with parts of steps of B, C, and D that are associated with intermediaries and their dynamic feedback loops affecting the focal firms. The above process tracing technique, i.e., identifying the intervening causal process between two "variables" or "constructs" (George \& Bennett, 2004; Gerring 2007a, Hall, 2006), involves a careful creation of a causal chain of evidence from observations (Gerring, 2007b). Sayer (1992: 243) asserts that inquiries into causes (as opposed to regularities) - typified by questions such as "What produces a certain change?" - require an "intensive" research approach, typically involving a qualitative, in-depth study of "individual agents in their causal contexts".

This paper uses an active single-case study design (Shee, 2006) to identify the organization change process and then seeks confirmation via other cases. Larsson \& Lowendahl (1996) in Lee, Mitchell \& Sablynski (1999) cite three main areas for evaluation: (1) authenticity, i.e., the case report is representative of the field experience, (2) plausibility, i.e., the case report makes intuitive sense to the reader, (3) criticality, i.e., the reader could actively re-examine the assumptions that underlie the case. With regard to authenticity and criticality, the author personally observed each case, had access to all written correspondence 
associated with the cases and interviewed key personal regarding their behaviour in the cases. The plausibility criteria are discussed in the main body of the case.

\section{Data Collection and Analysis}

Birkinshaw, Brannen, \& Tung, (2011) found one of the most frequent problem with the submissions on qualitative research was that they did not give any explanation of how the data were obtained or analyzed. As indicated above, the author was fortunate to gain access to the alliance formation process in this case, literally from its beginning. Most conversations and correspondence among the brokers and the two firms took place in English. One broker and the Taiwanese firm representative both achieved undergraduate and advanced degrees in the United States and were both fluent in English and Taiwanese. The author was invited to observe by one of the brokers in the transaction. Similar to (Arino \& Ring, 2010) the author also took notes of less formal discussions around meals and during breaks of other details related to the initial meetings. Other data sources, including archives, letters of intent, contracts, phone conversations and interviews, were used to triangulate the primary observations data (Eisenhardt, 1989).

\section{Case}

A contextual explanation analysis demands a rich picture of how the complex interactions of friendship, business practices, ethnicity, cross-national culture (American vs. Chinese) and organizational culture can contribute to conflicts, how these conflicts were resolved, and how cross-cultural brokered relationships ultimately affected integration of the acquired subsidiary. A detached-participant/observer approach is appropriate because it facilitates the building of the necessary rapport with the subjects to allow them to talk freely about these issues of a sensitive nature (Brannen, 2004).

Similar to Pratt \& Rosa (2003) and Van de Ven \& Poole (1995), this analysis used a real world account to develop a representative categorization scheme to aid in proposition development and theory extension. A narrative was employed to tell the story. Next "events" similar to Arino \& DelaTorre (1998) and Beamish and Lupton (2009) were constructed in order to categorize the data. Then discrete events were identified that involve creating a common meaning that captures specific activities associated with the third-party deal making procedure. These events represent specific actions taken by the players and when woven together, represent an alliance process narrative and a resulting behavioural model. (See Table 1 where each event is identified, followed by a discussion of the relevant logical threads associated with the interrelationships among cultural attributes, social networks, and third-party intermediaries.)

Another way of looking at the eleven events is that each was required to either directly or indirectly, contribute to the partial solution to the four main problems facing the alliance creation process of the two firms.

Problem 1: The Taiwan firm (Enviro) seeks to grow, but cannot develop technology internally and seeks a strategic partner, but does not know who. (Discovery Process/Explanatory Construct)

Problem 2: On paper, the U.S. firm (USFIRM) looks acceptable, but Enviro wonders: "Can we trust/work with these people?" Is an Enviro-USFIRM partnership possible? (Plausibility Assessment/Mediating Construct)

Problem 3: Is the deal fair? Third party evaluators enter the equation for both sides. (Fairness Evaluation/Mediating Construct)

Problem 4: Do we have a deal? Final Commitment (The Deal and Next Steps/Dependent Construct)

How the firm addresses each of the problems provides a structure for grouping the events into four distinct phases similar to Beamish and Lupton (2009). (See Table 2.) The main case narrative presented in Attachment 1 expands on the events summarized in Table 1 and is used to solve the core problem associated with developing a SME international alliance. 
Table 1. Events and Activities Associated with SME International Alliance Process

\begin{tabular}{|c|c|}
\hline Events & Activities \\
\hline $\begin{array}{l}\text { Event 1: Decision by } \\
\text { Taiwan Parent to } \\
\text { Reconsider Taiwan's } \\
\text { Subsidiary's (Enviro) Role }\end{array}$ & $\begin{array}{l}\text { The selection of Peter, a trusted friend, reduced operational uncertainty from the president's perspective and also } \\
\text { introduced a possible future growth option for the subsidiary. The social network ties between Peter and the head of } \\
\text { the Taiwanese parent firm were direct and strong. }\end{array}$ \\
\hline $\begin{array}{l}\text { Event 2: Enviro's Leader } \\
\text { (Peter) Explores } \\
\text { Opportunities with His } \\
\text { Internal Business Network }\end{array}$ & $\begin{array}{l}\text { The subsidiary's turnaround removed exogenous uncertainty associated with day-to-day market operations but } \\
\text { introduced endogenous strategic uncertainty associated with the funding of long-term growth. }\end{array}$ \\
\hline $\begin{array}{l}\text { Event 3: Peter Retains } \\
\text { Consultant (Jane) Who, in } \\
\text { Turn, Contacts Her Peer } \\
\text { Network }\end{array}$ & $\begin{array}{l}\text { Peter sensed that a U.S. firm might be an answer to his expansion plans, but did not know any candidate firms. A } \\
\text { structural hole existed between Enviro and a candidate U.S. firm. Peter chose to tap into his extended business/social } \\
\text { network to seek advice from Jane about a potential U.S. partner. Jane represented a weak tie to Peter and this is } \\
\text { consistent with the Granovetter (1973) finding of weak ties being key information bridges. } \\
\text { Joe, Jane's business school classmate, had been running a middle market boutique M\&A business for several years } \\
\text { so he had contacts with many potential U.S. alliance partners. Jane would serve as the network bridge between Joe } \\
\text { and Peter. Though the ties between Joe and Peter were not direct, Peter trusted Jane and as such, implicitly trusted the } \\
\text { relationship, consistent with Simmelian three-person clique structure. }\end{array}$ \\
\hline $\begin{array}{l}\text { Event 4: Joe Taps his } \\
\text { Network and the Options } \\
\text { Increase }\end{array}$ & $\begin{array}{l}\text { Peter relied on Jane to understand his information request and provide him selective information, enough to answer } \\
\text { his internal questions but not too much to create information overload. Joe used his weak network ties to several } \\
\text { business networks to identify and cull possible joint venture candidates. With regard to the communications, } \\
\text { misunderstandings were minimized because Jane (who had worked with Chinese firms before) was the sole } \\
\text { information bridge with Peter, Jane only communicated with Joe and Joe would be the only contact with the U.S. } \\
\text { firms. This arrangement clearly placed the power to bring the alliance together with the third parties in a classic } \\
\text { tertius gaudens arrangement. }\end{array}$ \\
\hline $\begin{array}{l}\text { Event 5: A U.S. Candidate } \\
\text { (USFIRM) is Identified }\end{array}$ & $\begin{array}{l}\text { Jane knew from Peter the type of company he wanted as a partner. Jane and Joe acted as central intermediaries who } \\
\text { could screen out many companies without telling Peter of each. If Peter had been involved, he would have felt an } \\
\text { obligation to discuss each candidate with the President, thereby significantly slowing the process. Jane and Joe } \\
\text { identified a focal firm, USFIRM, for Peter to discuss with the President. Problem } 1 \text { is solved. Exogenous uncertainty } \\
\text { associated with partner identification was resolved. In effect, Joe and Jane bridged the structural hole; they closed the } \\
\text { strategic, informational, geographic, and cultural distance gaps between Enviro and a possible U.S. partner. }\end{array}$ \\
\hline $\begin{array}{l}\text { Event 6: Potential Deal } \\
\text { Team Formalized, } \\
\text { Negotiations Begin }\end{array}$ & $\begin{array}{l}\text { Exogenous uncertainty existed for Enviro, could it trust USFIRM? Stated another way, could Peter trust Jane who } \\
\text { trusted Joe who trusted Ralph and vice versa? Could the structural hole between Enviro and USFIRM be bridged by } \\
\text { the third-parties? } \\
\text { Relational investment associated with third-party intermediaries was valuable because personal connections } \\
\text { substituted for mistrust and lack of familiarity. More specifically, connected nodes -Peter (Enviro), Joe (Broker), } \\
\text { Jane (Broker), Ralph (U.S. Alliance representative)- in the deal network archipelago were embedded in dense } \\
\text { informational, strategic, geographic and social networks. Misunderstandings could be blamed on the third parties, } \\
\text { thus permitting the focal companies to save face while changing positions. If there were no third parties at this point, } \\
\text { each deal point would probably have been detailed in writing to accommodate the lack of trust between the parties } \\
\text { and the high uncertainty avoidance tendencies of Taiwanese culture. This would have likely complicated negotiating } \\
\text { and increased the potential for misunderstandings that could turn quickly in mistrust between the parties. }\end{array}$ \\
\hline $\begin{array}{l}\text { Event 7: Investment } \\
\text { Decisions Put Firms on an } \\
\text { Irreversible, } \\
\text { Path-Dependent Trajectory } \\
\text { for Future Development. }\end{array}$ & $\begin{array}{l}\text { If the process of developing the alliance becomes focal unit, then uncertainty is endogenous. The alliance team had to } \\
\text { internally create the strategic plan that would be presented to the parent companies. Once again the chain of } \\
\text { bi-directional network connections (Peter-Jane-Joe-Ralph) was instrumental in broaching new ideas and helping } \\
\text { bridge conceptual structural holes for the deal network. At this phase, experience, technical information, intentions } \\
\text { and trust were all critical ingredients being blended together in the alliance network team. } \\
\text { Problem } 2 \text { is solved: A high-level deal structure that meets both parties' goals appears feasible and a functioning } \\
\text { network had been formed among the third parties and the principals. }\end{array}$ \\
\hline $\begin{array}{l}\text { Event 8: Deal Structure } \\
\text { Evolves Along Basic } \\
\text { Principles of Fairness, Trust } \\
\text { and Closure }\end{array}$ & $\begin{array}{l}\text { Jane and Joe tailored the discussion particulars to reflect the leaders' intentions; however, the due diligence team and } \\
\text { associated information counterparts in Enviro were beginning to build network bonds, due to familiarity gained by } \\
\text { working with each other. A broker exhibiting traditional tertius gaudens behavior would attempt to keep } \\
\text { organizations separate to maintain his/her power position; however, in a deal structure network this is not desirable or } \\
\text { possible. }\end{array}$ \\
\hline $\begin{array}{l}\text { Event 9: Problems Arise, } \\
\text { Negotiations Bog-Down }\end{array}$ & $\begin{array}{l}\text { The companies' lawyers operated within their own sub-network and attempted to memorialize the alliance } \\
\text { agreement in a contract. They inserted seemingly benign language relating to the Board that called into questions } \\
\text { months of relational trust among Peter, Jane, Joe, and Ralph. Both third-party intermediaries quickly entered the } \\
\text { picture and changed the language. Joe assured Jane that it was not Ralph's intent to control the Board and Jane } \\
\text { persuaded Peter that this was just one big misunderstanding. The deal network team had built up a reserve of trust } \\
\text { that carried them through this trying time. } \\
\text { Problem } 3 \text { is solved: The deal is deemed to be fair by lawyer and other outside arbitrators. }\end{array}$ \\
\hline $\begin{array}{l}\text { Event 10: Options and } \\
\text { Incentives Finalized }\end{array}$ & $\begin{array}{l}\text { The solution permitted both firms to save face because of the centrality of the third parties to the negotiations. } \\
\text { Exogenous uncertainty was resolved and relational mistrust abated. }\end{array}$ \\
\hline Event 11: Deal Signed & $\begin{array}{l}\text { At this point problem } 4 \text { is solved. The alliance had become a fully functioning organization with its own social } \\
\text { network and strong direct ties to both parents. }\end{array}$ \\
\hline
\end{tabular}


Table 2. Relational Model

\begin{tabular}{|c|c|}
\hline Problem Statement & DSNT \\
\hline $\begin{array}{l}\text { Problem 1: Enviro (Taiwan Firm) } \\
\text { seeks to grow, but cannot develop } \\
\text { technology internally. Therefore it } \\
\text { seeks a strategic partner, but does } \\
\text { not know whom to select. }\end{array}$ & $\begin{array}{l}\text { Structural hole exists between Enviro and USFIRM } \\
\text { Exogenous uncertainty exists along the following dimensions: strategic, informational, geographic, and/or } \\
\text { cultural distance. } \\
\text { Jane possesses high level of network centrality and is well positioned in dense informational network. } \\
\text { Jane (3rd party intermediary associated with Enviro) contacts Joe (3rd party intermediary associated with } \\
\text { USFIRM); relational "investment" is valuable because Joe is well connected. } \\
\text { Exogenous uncertainty resolved; A potential partner is identified. } \\
\text { Jane bridges structural hole; helps closes strategic, informational, geographic, and cultural distance gaps. }\end{array}$ \\
\hline $\begin{array}{l}\text { Problem 2: On paper, USFIRM } \\
\text { looks good, but Enviro wonders: } \\
\text { "Can it trust/work with USFIRM?" } \\
\text { Is an Enviro-USFIRM alliance } \\
\text { possible? }\end{array}$ & $\begin{array}{l}\text { Lack of relational trust causes exogenous uncertainty (i.e., exogenous to Enviro, but endogenous to the } \\
\text { alliance) } \\
\text { Structural hole exists between Enviro and USFIRM } \\
\text { Jane and Joe serve as trust-building mediators between Peter (Enviro Representative) and Ralph (USFIRM } \\
\text { Representative); relational "investment" is critical because personal connections substitute for mistrust/lack } \\
\text { of familiarity. } \\
\text { Connected network nodes (Peter, Jane, Joe, Ralph) embedded in dense informational, strategic, geographic } \\
\text { social network. } \\
\text { Chain of bi-directional network connections (Peter-Jane-Joe-Ralph) bridges structural hole; experience, } \\
\text { technical information, intentions, trust, flow through network chain. }\end{array}$ \\
\hline $\begin{array}{l}\text { Problem 3: Is the deal fair? Third } \\
\text { party evaluators enter the equation } \\
\text { for both sides. }\end{array}$ & $\begin{array}{l}\text { Exogenous uncertainty introduced by lawyers and accountants evaluating the deal. } \\
\text { Exogenous uncertainty resolved; relational mistrust abates }\end{array}$ \\
\hline $\begin{array}{l}\text { Problem 4: Do we have a deal? Next } \\
\text { steps }\end{array}$ & $\begin{array}{l}\text { If successful, deal is signed. } \\
\text { Alliance becomes is own social network, ties remain with parents } \\
\text { Jane and Joe exit alliance, contrary to traditional social network theory. }\end{array}$ \\
\hline
\end{tabular}

\section{Proposition Development}

Proposition development involves the process of making sense of the observable world by conceptualizing, categorizing and ordering relationships among observed elements, (Andersen \& Kragh, 2010). As indicated earlier, the analysis is initiated by the goal of the firm to find an alliance partner; however, the proposition development that explains SME international alliance behavioural process is discussed in the context of the Explanatory, Mediating and Dependent construct framework.

Explanatory Construct: Does the SME Alliance process cover the same basic lifecycle as large business alliances?

The alliance lifecycle processes for large firms are well documented, e.g., previous Lotus and HP examples. For these firms, Beamish and Lupton (2009) developed a phased approach in the identification of management issues during the partnership screening process; while Dyer, Kale \& Singh (2001) enumerate five main stages associated with alliance lifecycles. Although, the SME international process was thought to be less formal and more organic in nature, the case analysis revealed eleven distinct events that the firm experienced in the creation of the alliance. (See Table 1.)
These case events appeared to conform to and were grouped into the four broad alliance phases framework (see Figure 2 and a more detailed explanation in Attachment 1) which are quite similar to the five alliance stages identified by Dyer, Kale \& Singh (2001).

Life Cycle Stages

(Dyer, Kale \& Sing, 2001)

(1) Business case/needs assessment and $3^{\text {rd }}$ Party Selection

(2) Partner Assessment \& Selection Screening and Identification

Case Phases (Internal Case)

(1) Need Analysis

(2) Candidate

3) Alliance Negotiation and Selections(3) Deal Structure and Evaluatory Metrics

(4) Alliance Management \& Beyond

(4) Deal/No Deal

(5) Alliance Teams

There is no conclusive statistical test to prove that the above staged international alliance process framework for SMEs is identical to that of large firms; however, support demonstrated in Figure 2 and the above stage and phase comparison for the proposition appears to offer very strong support. 


\section{Mapping of Events into Broad Option Categories}

\section{Phase 1}

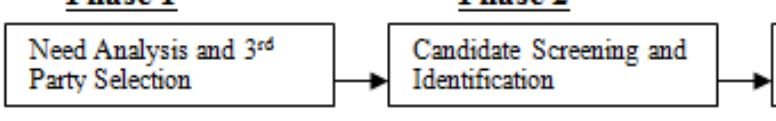

Phase 3

Deal Structure and Evaluatory Metrics
Phase 4

Deal No Deal \& Beyond

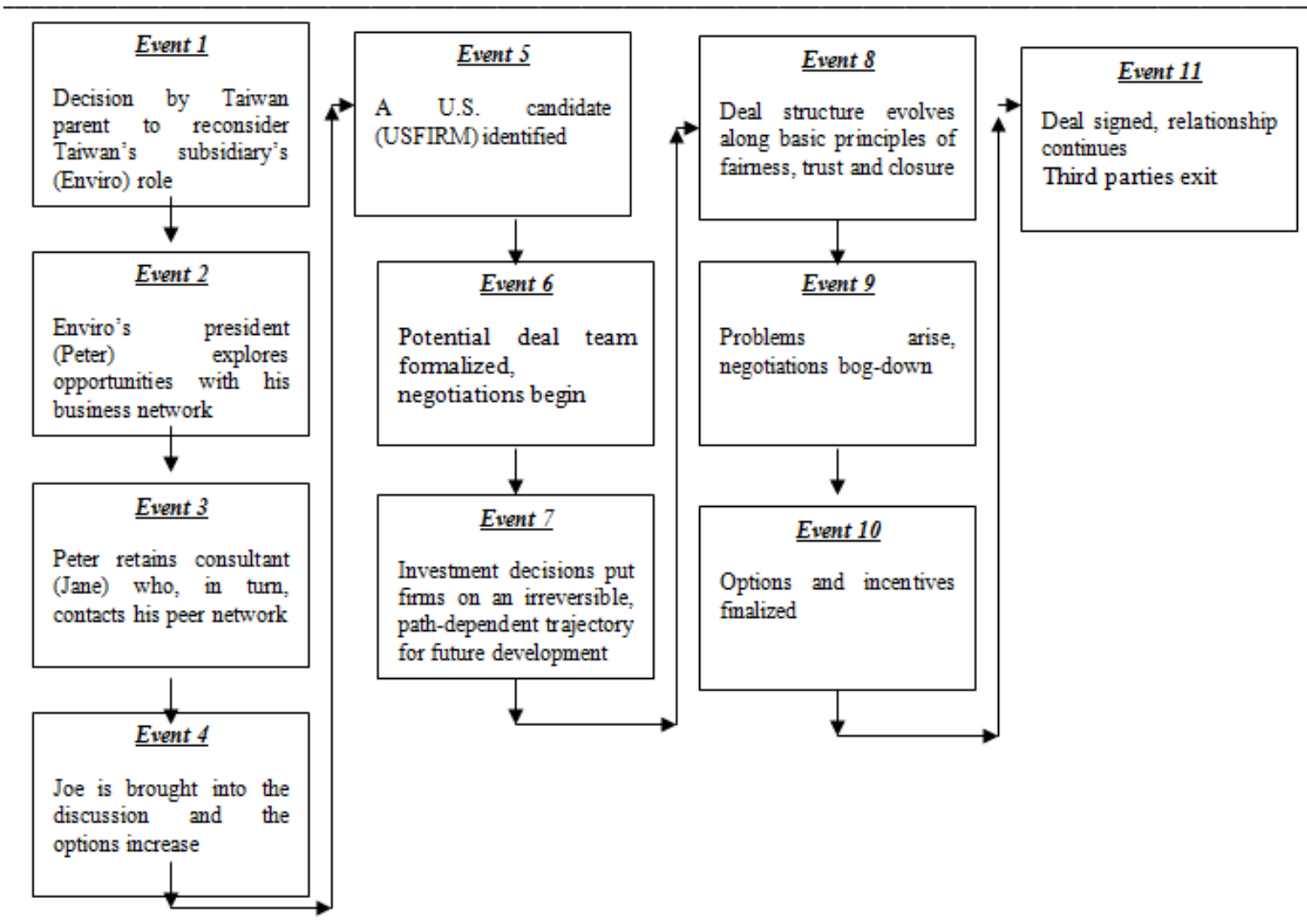

Figure 2. Mapping of Events into Broad Option Categories

Proposition 1: When big and small firms seek an alliance, the life cycle stages framework of the basic explanatory construct for alliance creation is categorically similar.

\section{Mediating Construct: How is the international alliance match making (partner discovery and deal negotiations) process different between SME and their large counterparts?}

In addition to formal operating procedures to guide the firm through life cycle stages of alliances, large firms also have specific resources dedicated to making alliances both a strategic and financial success (Dyer, Kale, Singh, 2001). Many of these large firm resources are tacit in nature and involve experiential learning from previous alliance successes and failures. Simonin (1997) highlights the need for large firms to turn previous alliance experience into greater "know-how." The areas he highlighted include: (1) Better partner identification and selection, (2) More skilled negotiation of terms and structure, (3) Improved monitoring and monitoring of collaborations and (4) Knowing how and when to terminate alliances. Increased collaborative know-how can provoke more informed decisions about further collaborations and more realistic and achievable objective setting for collaborations. Similarly, Gulati in his various contributions has focused on how previous alliances can help in the success of future alliances, particularly if the future alliance is with the same firm.

Unlike a large firm, SME leaders construct a narrative in their mind that solves the main perceived problem associated with Phase I. They identify a feasible final outcome and then work backwards to achieve it. They first look internally for answers, but if the problem, e.g., an alliance partner, is beyond the firm's scope, they seek mediation assistance and often tap their serendipitous network, one of their most rare and immutable resources. The somewhat opaque process they use to leverage this personal, knowledge-based asset requires analysis. SMEs often turn to serendipitous networks to bridge structural holes which is consistent with Granovetter (1974) previous network studies that showed informal ties, rather than close friends, are more likely to lead to the finding of new jobs in employment networks. By analyzing this key mediating variable that bridges the 
structural hole, a better understand of the mechanisms that directly influence alliance development, and the chain of events through which those mechanisms exert their influence was sought and achieved (Dearing \& Hamilton, 2006)

Enviro had no dedicated staff to identify potential partners. Without outside help, Enviro was organizationally and geographically isolated, like some 1 million other SMEs in Taiwan (Shee, 2006). In Enviro President's (Peter) conceptual plan, there was a structural hole between his social network residing in the Taiwan subsidiary and the envisioned U.S. alliance partner. One could look at Figure 1 and quickly conclude that Peter sought, a third party intermediary, Jane, (who eventually needed a college classmate in the M\&A business, Joe) to bridge the structural hole and mediate the relationship between the Taiwan firm and a U.S. alliance partner. Peter, who did not have the time, resources or expertise to evaluate potential alliance partners, would have to rely on Jane to perform many of the functions done by the large firms' internal staff; however, Jane's motivation and approach would be governed by her relationship with Peter and Joe rather than some internal firm policy guidelines that would be present in a large firm. The Mediating model addresses how alliance partners can be linked indirectly with third parties being the vehicle for this. By completely bridging the structural hole, third parties complete the mediation process.

Proposition 2: When big and small firms seek international alliances, how candidate firms are identified and united is quite different, with the former leveraging dedicated internal resources and established policies, while the latter require an extra-firm, mediating construct to identify and evaluate potential partners.

The mediating construct initial proposition confirms the need for extra-firm resources embodied in brokers to create a successful alliance; however, the case study further reveals how the chain of events associated with the broker relationships among themselves and with the focal firms change over time to conform to the requirements of the dynamic alliance creation process.

Specifically, Peter sensed that his boss thought that Enviro, even with its improved profits, was a poor fit with the rest of the company's businesses. Building on his boss's cue, Peter created a mental picture of a feasible alternative. The first alternative explored was to tap into his serendipitous network of old friends to seek counsel in an attempt to find an alliance partner, his conceptual goal. In this case, Jane, the third party contacted, did not have sufficient knowledge to bridge the structural hole so she had to tap into her serendipitous network of executive MBA classmates and contact Joe. Joe did have a business network that included U.S. environmental firms, so he was able complete the information triad. While these networks were being linked at the conceptual level, no specific information regarding potential contacts was being shared.

A careful look at this broker evolution is critical to the success of the alliance and the future success of the broker as an on-going business entity. It has rarely been studied because it requires the close monitoring of behaviours over time and the candid assessment of roles and responsibilities of key members in an uncertain, unfolding process. The discussion of propositions associated with changing mediating behaviours of the brokers during each phase of the alliance framework generates micro-level insight rarely observed in an actual business context.

$3^{\text {rd }}$ Party Selection- Phase 1

Proposition 2a relates to the SME solution to the generic "Candidate Identification Problem."

Proposition 2a: If the contextual conditions are very uncertain as in Phase I of the SME model, then third party intermediaries out of necessity become effective international alliance brokers and they exhibit opportunistic behaviours.

Both Jane and Joe were exhibiting tertius gaudens (opportunistic) behaviors in seeking to leverage their brokerage role into a financial return for identifying an alliance partner; however, Jane and Joe had to provide Peter enough information on the merits of an alliance and its likelihood of success to get Peter's interest piqued in pursuing the project further. In this phase, the structural hole was between an unknown U.S. firm and Peter, and Jane and Joe had to sell the concept of how they potentially could bridge the structural hole, but not identify the potential partner. With regard to Proposition 2a, Peter's most constrained resources were time and management focus. The tertius gaudens behaviors exhibited by Jane and Joe (keeping Peter removed from the candidate and the screening process) allowed Peter to concentrate on his day-to-day business activities while the alliance process was outsourced to Jane. Of course, Peter had to believe that Jane would produce an acceptable candidate at the end of the process, while Jane and Joe had to believe that their successful brokering efforts would produce a financial reward, but there were no guarantees. Jane and Joe were gaining social capital with Peter, but both felt they needed to maintain their tertius gaudens position for the time being.

Candidate Identification - Phase 2

Proposition $2 b$ relates to the SME solution to the generic "Plausibility Assessment" problem.

Proposition 2b: If the international alliance firms use compensation contracts with third party intermediaries in Phase 2, then third party intermediaries orchestrate a transition in their behaviour from one of opportunism to one of alliance shared benefit, thereby increasing information flow among all alliance participants.

In Proposition $2 b$ an intangible asset (alliance concept) is turned into a tangible one (contract) between Jane and Peter. At the beginning of Phase II, Peter proposed and signed a contract with Jane to perform the matchmaking function for Enviro. Joe had previously dealt with Ralph's firm on M\&A deals so he had a standing contract with USFIRM when the Enviro alliance was proposed. Interestingly there were no contract ties between Joe and Jane, but both would get paid only if there were a successful alliance, so they always maintained a mutual tertius iungens (cooperative) 
relationship. The contracts and the compensation structure maximized tertius iungens behaviors among all parties and virtually eliminated tertius gaudens third party behaviors. Peter used the typical tertius gaudens behavior of a free agent matchmaker as a justification with his boss for the need for a contract, but he also used cooperative tertius iungens behavior with his friend Jane to insure her that he was not going to anyone else with this idea.

Proposition 2c: When the alliance formation process transitions from Phase 2 to Phase 3, the role of third parties dramatically changes from one of being the central actor (a bridge connecting a structural hole) to one who monitors and facilitates actions of a task specific set of central actors and only gets involved when problems occur.

After a few high-level meeting between Ralph and Peter to establish information sharing guidelines between the companies, the number of network nodes and ties associated with the evaluation process increased dramatically. In network terms, dynamic non-hierarchal routing took place, i.e., relatively low-level people in each organization were encouraged to contact their counterparts directly to obtain product, technology and market information. Joe contacted Jane or Ralph only if in his estimation the evaluation process was getting bogged down. The respective firms' low level teams kept their management informed, but Ralph and Peter's communication was very infrequent. Technical information was bridging the structural hole between the potential alliance partners, but third party mediators only got involved on an exception basis. The common knowledge spheres (environmental engineering) of the lower level employees appeared to mitigate cultural conflicts. Also, USFIRM had some Taiwanese managers to further lessen any potential cultural problems.

Proposition 2c is consistent with Kilduff \& Tsai (2005) call for the increased study of the evolution of networks and the roles of the players in them. A better understanding of the dynamic network properties is critical to alliance creation. The central actors transition from a lead to a monitoring role can be viewed as an extension of tertius iungens behavior, i.e., each player performing whatever activities are required for the success of the whole with little regard to the perception of his/her individual role. Third party intermediaries clearly relinquished their leadership powers here; however, they still performed a critical oversight role.

Deal Structure- Phase 3

Proposition 2d relates to the SME solution to the generic "Fairness Assessment" problem. The deal structure problem relates to a common set of assumptions that drive the deal, how performance is to be measured, how day-to-day operations are to be managed and the understanding that both sides are attempting to be fair and have the interest of the partnership at heart.

Proposition 2d: As the deal structure matures and the main alliance partners internally delegate the numerous related tasks associated with pursuing a successful alliance in Phase 3 , then a variety of self-centered, sub-networks with associated sub-goals begin to appear among the alliance partners.

In Phase 3, each sub-group of actors, e.g., accountants, lawyers, etc, evaluate from their own professional perspectives the fairness of the terms and conditions of the final deal proposal. They had direct access to their respective bosses, Peter and Ralph, and their professional counterparts in the other firm, so communication was direct. Also, the overarching goal of these players was to find any issues with what was crafted to date, not to make the overall alliance work. Goal incongruity between these professions and that of the original team and its leaders had the potential to create considerable cross-team friction. When problems arose, they quickly escalated within the respective organizations and minor misunderstandings became potential deal breakers.

Proposition 2e calls into question traditional assumptions regarding direct and full communication as being the first best solution.

Proposition 2e: As new sub-group players enter, third parties can use themselves as communication buffers to mitigate misunderstanding between culturally distant and professionally centered groups.

Particularly in cross-cultural communications, misunderstandings and inferred motives can lead quickly to positions that are deal breakers. Third parties can step in and position themselves as the reason for the misunderstanding that created new structural holes between the two firms and allow the parties to save face and get the negotiations back on track. They can also provide context though historical accounts that address issues involving intent which may be viewed by one party as benign but by the other as a deal breaker.

One such occasion arose during a disagreement about Board seats, Joe and Jane were notified of the issue, identified the root problem, and quickly mediated the dispute by placing some of the blame for the misunderstanding on them rather than the involved parties. In this case, the third parties created a temporary structural hole between the parties to permit cooling off and a rational assessment of intent associated with the misunderstanding.

The number and importance of mediating construct propositions associated with the chain of events highlight the critical importance that third parties play in the creation of SME international alliances. The richness of the case data permits the identification of these effects.

\section{Dependent Construct: Do We Have a Deal or Not?}

Proposition 3 relates to what are the likely next steps for the involved parties and how they leverage the knowledge and relationships gained in this partnership in other areas of the business.

Proposition 3: If brokers are successful in bridging structural holes and creating a successful alliance deal, then they create positive social capital among members of the social network and this sets the stage for future coordinating activities, tertius iungens behaviors.

Much like Gulati (1998), once a third party helps a firm create an alliance, they are in a favored position to help them 
in the future. In Phase 4 (deal/no deal and beyond), an alliance was formed and the goal of the teleological process model was achieved. A new goal could be determined for all the related parties to share or the third parties could go their separate ways. However with a successful alliance, positive social capital has been created in the tie between Peter and Jane, and Peter would look to Jane to coordinate actions again for him in the future. Also, a referral network between the alliance partners' business contacts could benefit Peter and Jane's future matchmaking business.

\section{Theory Implications}

The case study is used to better understand the behaviors of, and critical roles played by third party intermediaries in the creation of international alliances. Collectively it provide insight into both process theories of Poole, et al. (2000) and the network theory of Burt (2000), Obstfeld, (2005) and alliance theory of Gulati (1998) in several ways:

- Goal oriented teleological models that begin with final causality and work backward appear particularly appropriate to explain international partnering activities. The end state, an alliance, attracts a chain of events, drawing the central subjects along a predictable phased path. The analysis has shown at the macro-phase level, the alliance process exhibits a temporal sequence with identifiable phases and is quite similar between large and small firms. This analysis identified four distinct and linked phases $\left(3^{\text {rd }}\right.$ party selection, candidate identification, deal structure, deal/beyond).

- However, out of necessity, extra firm networks tend to play a more pronounced role for the creation of alliances for smaller, culturally diverse firms. Instead of formal plans and dedicated teams as would be the case for larger firms, individual leaders of these smaller firms construct a mental model of a completed alliance and then seek out intermediaries to fill in the missing pieces. Propositions associated with unpacking the critical and dynamic third party roles for SME international alliance creation is a major contribution of this paper.

- More specifically, SMEs use relational models involving trusted third parties to become key informational bridges between structurally separated firms for international alliance partners. Business at the SME level (vs. large MNE) is much more social and personal, therefore a critical component of understanding the SME international alliance process, involving how third partners uniquely mediate this relationship, is decomposed into specific propositions. Leaders of SMEs often seek to apply information gathered from their day-to-day activities to their business operations in a synergistic fashion. Because of expediency and cost, they tap third party relationships rather than do business research to bridge structural wholes. Third party intermediaries' behaviors appear unique to particular phases and change between phases, transitioning from tertius gaurdens to tertius iungens actions for a successful alliance.

\section{Limitations}

The first-hand account of the case could be viewed as potentially biased. As with any research method, there are compromises. In this approach, richness of information was viewed to outweigh the small possibility of bias. However, five precautions were taken to mitigate the effect of any potential bias. First, cultural bias, a one-person account could occur by the American author, was mitigated because the issues were discussed from both an American and Taiwanese perspective before they were reported.

Second, not all sides of the negotiations would be accurately represented in the reporting of the cases. Rich dialogue was shared among all involved partners. A high level of trust existed between the U.S. and Taiwan business advisors because they had been classmates in graduate school. Trust and open communications occurred between the two companies and their respective advisors because they had previously done successful deals.

Third, there was limited disclosure of information by the companies, creating a biased account of the transaction. Full disclosure of information was not a problem because the author previously knew the U.S. and Taiwanese firms' advisors who were central to the success of the transaction.

Fourth, the author could not recollect the completed transaction after several years. The author did not have to rely solely on his memory of the deal after several years because there was an extensive paper trail in his records. The transaction involved companies in distant time zones and the parties were from distinct cultures; therefore, a great deal of the communications was in writing.

Fifth, that the deal structures used here to create the alliances were unique. The U.S. and Taiwanese firms' advisors used similar approaches in creating other alliances between U.S. and Chinese and European firms. What are unique here are the reported details associated with creating and bridging social networks and the negotiation process including cultural nuances in the context of third parties.

Another possible limitation associated with any single case study or limited multiple case analyzes, is that the case may not be representative of the population. The brokerage process used here by Jane and Joe were used by them in other successful alliances between U.S. and European firms not specifically studied as part of this analysis. They also indicated that there were also many other boutique alliance bridging firms performing similar functions in New York City.

The study did not permit us to make specific propositions regarding how third-party intermediaries would more likely be required for firms that are geographically and culturally distant from one another than from firms that are closer geographically and more similar in culture. Because our 
study did not look at countries other than the U.S. and Taiwan, it did not truly build in variance in (national) cultures and geographic distance. For this comparison to be made, the research design would need to include alliances between firms that are culturally similar and/or geographically proximate to Taiwan and the U.S. Future studies need to address this research area.

\section{Conclusions}

The intent of this research is to address an interesting topic of both theoretical and practical relevance and to add knowledge associated with process research and longitudinal studies, especially in the field of social network evolution and alliance deal making. It uses a somewhat non-traditional, empirical approach, i.e., narratives, events, phases and propositions, to explore the complex dynamic relationships that define the phenomenon under study.

In the analysis it is depicted how a case narrative can be used to identify key events that define the goal driven alliance creation process for a culturally diverse joint venture. The associated teleological process identifies a particular four phase pattern and identifies how third parties aid in the alliance creation process, which is consistent for both large and small multinationals. The analysis then identifies and explores differences between large and small multinational alliance creation process focusing on the mediating construct associated with the role third party brokers play. Distinctive propositions are developed that demonstrate how these third party networks are different from the way large firms create alliances. The central tendencies associated with these third party/firm relationships are decomposed and the evolution of third party behaviours from tertius gaudens to tertius iungens is identified.

The analysis has shown how final and formal causality drive the alliance creation process and the very important role third parties play in the bridging of informational structural holes. Although third parties can exhibit both tertius gaudens or tertius iungens behaviors in the first stage of the process when trust is being established and compensation issues are being finalized, the majority of their time is associated with tertius iungens behaviors associated with the creation of a successful alliance. An interesting fact, the morphing of third party behaviors, the changing of central actors, and the creation of relevant sub-networks all argue in favor of dynamic rather than static social network in process analysis. Third parties were also found to be not just information brokers but rather skilled network intermediaries who must be aware of cultural differences in the negotiation process and look to build social capital that can be leveraged in further relationships. The analysis also demonstrated via propositions that dynamic social network research can be eclectically combined with narratives and process theory to greatly improve the understanding of causal relations in the international alliance evolution process particularly for SMEs.

\section{Attachment I}

\section{Background}

The industry setting for the case study is the environmental consulting and engineering industry in Taiwan. The study of the industry reveals that there had been significant liberalization over the previous several decades, rapid technological change that had put pressure on local players to use the latest technology, and a relaxation of institutional constraints regarding foreign ownership. Two other industry dynamics deserve mentioning: Many Taiwanese firms looked to the U.S. market to gain technological expertise, and many U.S. firms sought Taiwanese partners to gain a foothold in that market and to help them learn about and eventually penetrate the rapidly growing infrastructure market in Mainland China.

Interviews with management reveal that the Taiwanese firm, the fourth leading Taiwanese company in the industry, (named "Enviro") did not have any previous alliances, while the U.S. firm, (named USFIRM in this analysis) which was over three times the size of the Taiwanese environmental firm, had completed several alliances in both its home market and in Europe. The third-party intermediary associated with the U.S. company, an investment banker and M \& A specialist named Joe, had put together several of the USFIRM's previous alliances. The third-party intermediary of the Taiwanese firm, Jane, was a consultant for several Hong Kong companies and had a social association with the Taiwan firm's leader, Peter, but not a current business relationship. (The names of the firms and managers were changed so that a freer dialogue and a more in-depth analysis could be reported.)

The case took place over a three-year period. The author observed the leaders' behaviors (Peter for Enviro and Ralph, the chosen representative of the United States alliance partner) during the entire process from idea conception through the candidate identification, and deal signing. Jick (1979) indicated that there is practical utility in having the researcher intimately familiar with the research setting. The author was present at some of the critical meetings both in the United States and in Taiwan, but got the majority of the factual information from a business school classmate, who was originally from Taiwan, attended virtually all the meeting and provided a written account of what happened. The business school classmate, Jane, had had previous business experience with both the Taiwan company officials and the investment banker, Joe. Because of these long-term relationships among the involved parties, there was considerable communication and information flow during the entire strategic alliance process. Van Maanen (1979) pointed out that the author of qualitative research must identify and construct the context in which the behaviour takes place and must see that behaviour from the position of the originator before the author can interpret what a given piece of observed behaviour means. This intimate knowledge by the author of the context is critical to the analysis that follows. 


\section{Main Narrative}

A narrative contains a cast of characters, a plot that temporally structures the events and a denouement in which the fortunes of the characters change from what they were at the story's beginning (Griffin, 1993). The key to causality in a narrative is the character's identity, actions, and sense making processes, i.e., no other actions seem credible given who the characters are and the situation in which they find themselves.

The president of the Taiwan parent company was unhappy with the continued losses from its environmental subsidiary, Enviro. He selected a trusted friend and former business associate with Taiwan environmental experience (Peter) who happened to live in the United States to run the subsidiary's operations. Within a year, Enviro was profitable; however, Peter knew that the fundamentals of Enviro called for more investment and a long-term orientation, a dramatically different focus from the parent company whose profits were related to short term trading operations. Also, commuting between the U.S. and Taipei was difficult, so it would not be surprising if Peter looked for a solution that met both his business and personal goals.

Peter decided to contact his former business associate and friend, Jane, to discuss what he could do with Enviro in a resource-constrained environment. After the meeting, Jane contacted her business school friend (Joe) who had left a large investment bank to create a boutique investment banking firm targeting middle-sized European and Untied States environmental companies. Jane brought Joe in to increase overall market knowledge by bridging several business networks and to expand the number of possible options available to solve Peter's business problem.

Jane remarked to Joe: "This sounds like a classic case for an alliance. Enviro could get new technology and investment dollars, while a U.S. partner would get access to a new market. Have you worked with any firms that might be interested? Of course, at this stage we are only dealing in hypotheticals." Joe knew exactly what Jane meant: Let me test the waters with my existing client base, without revealing any pertinent information.

Joe discussed the qualifications of one impressive candidate firm, USFIRM, with Jane who contacted Peter. Peter was amazed at the speed of the discovery process, less than one month. Peter was very careful to explain the situation to his President, "this is just an exploration exercise, no commitments at this time." He also highlighted that an alliance/equity investment in the subsidiary would increase the subsidiary's earning potential while not requiring any additional parent firm resources. At this point, Peter was exploring the plausibility of the narrative, a negative reaction would have killed any further talks; however, Peter obtained a non-committal okay and talks continued.

Consistent with the initial discovery process, the wants and desires of the potential alliance partners were communicated through Joe and Jane. Each third party could quickly test parts of the structure with their respective company representative, Peter for Enviro and Ralph for USFIRM. Joe and Jane guided the emerging deal structure in the following areas: A minimum price the USFIRM would pay for Enviro in three years, technology sharing arrangements, price earnings multiples that would fix the future acquisition price, Board composition and voting, etc. During the terms and condition negotiations, USFIRM sent a team to Taiwan to conduct due diligence on Enviro and this started the relationship process among the working levels of the proposed alliance.

After a deal was formalized consistent with both parties objectives, Jane observed: "direct negotiations between the firms would have taken much longer and the number of options considered would have been fewer because each proposal and counter proposal would have had to have been in writing and cleared through the respective organizations."

Because USFIRM was expected to be the ultimate purchaser, the memorandum of understanding was written by the USFIRM's lawyers and surprisingly gave them the majority of the Board of Director (BOD) seats. Peter and Jane were stunned at this late language change because it significantly changed the deal incentives and had the potential to adversely affect Enviro's position. Enviro expected a 50/50 split of BOD seats because that was how the profits were to be distributed. If USFIRM controlled the Board and could dictate major decisions, such as when to take profits, they could dramatically affect the ultimate purchase price, which was tied to a future price/earnings ratio. A perceived breach of trust could have been fatal at this point in the deal if a face saving alternative could not be constructed quickly. Joe assured Jane that this was not the intent of USFIRM's lawyer or company representatives, and agreed that this condition had to be changed. Jane wondered: "how six months of trust and relationships could potentially be dissolved seemingly overnight by an inadvertent misunderstanding." Clearly, Joe and Jane's ability to ascertain the intent of the change and come up with a quick counter proposal defused the situation from becoming a bigger problem between the two companies. The solution was a 50/50 ownership structure and to have operational control remain with Enviro for the next three years and the number of board seats be fixed at three and three. If and when USFIRM increased its equity ownership in Enviro, then it would get the majority of Board seats. The contract change initiated by the third parties permitted the USFIRM and Enviro's management to save face and to proceed with negotiations.

The deal was signed and Enviro had the USFIRM as a partner, gaining its technical expertise and investment dollars. In return, USFIRM gained access to the Taiwan market with an option to pursue the much larger Mainland China market. USFIRM also obtained the option to purchase Enviro at an undetermined future price that was tied to the alliance's future performance via a fixed ratio. 


\section{REFERENCES}

[1] Abbott. A. 1988. Transcending general linear reality. Sociological Theory. 6. 169-186.

[2] Anand, B. N. \& Khana, T. 2000. Do firms learn to create value? The case of alliances. Strategic Management Journal, 21 (3): 295-315.

[3] Andersen, P. H. \& Kragh, H. 2010. Sense and sensibility: Two approaches for using existing theory in theory-building qualitative research. Industrial Marketing Management 39. 1.

[4] Arino, A. \& Ring, P. S., 2010. The role of fairness in alliance formation. Strategic Management Journal. Volume 31, Issue 10, 1054-1087.

[5] Arino, A. \& DelaTorre, J. 1998. Learning from failure: Towards an evolutionary model of collaborative ventures. Organization Science. 9 (3): 306-325.

[6] Beamish, P. \& Lupton, N. 2009. Managing Joint ventures. Academy of Management Perspective. 75-94.

[7] Beckman, Christine M; Haunschild, Pamela R; Phillips, Damon J. 2004. Friends or Strangers? Firm-Specific Uncertainty, Market Uncertainty, and Network Partner Selection Organization Science 15. (3) 259-275.

[8] Birkinshaw, Julian; Brannen, Mary Yoko; Tung, Rosalie L. 2011. From a distance and generalizable to up close and grounded: Reclaiming a place for qualitative methods in international business research. Journal of International Business Studies, suppl. Special Issue: Qualitative Research in International. 42 (5) 573-581.

[9] Brannen, M. Y. 2004. When Mickey loses face: Recontextualization, semantic fit, and the semiotics of foreignness. Academy of Management Review, 29 (4): 593-616.

[10] Burt, R.S. 2004. Structural holes and good ideas. The American Journal of Sociology, 110 (2), 349-399.

[11] Burt, R.S. 2002. Bridge decay. Social Networks. 24 (4). 333-363.

[12] Burt, R.S. 2000. The network structure of social capital. Eds. Sutton, R. \& Staw, B. Research in Organizational Behavior. JAI Press. Greenwich, CN. 345-423.

[13] Burt, R.S. 1992. Structural Holes. Harvard University Press. Cambridge, Mass.

[14] Chi, T. 1994. Trading in strategic resources: Necessary conditions, transaction cost problems, and choice of exchange structure. Strategic Management Journal, 15 (4): 271-290.

[15] Coleman, J. 1990. Foundations of Social Theory. Harvard University Press. Cambridge, Mass.

[16] Contractor, F. \& Lorange, P. 1988. Cooperative strategies in international business. Lexington, MA: Lexington Books.

[17] Coviello, N. E., \& McAuley, A. 1999. Internationalisation and the smaller firm: A review of contemporary research. Management International Review, 39 (3): 223-256.

[18] Coviello, N. E., and Munro, H. 1997. Network relationships and the internationalisation process of small software firms, International Business Review, 6(4): 361-386.
[19] Dearing, E. \& Hamilton, L. 2006. Contemporary advances and classic advice for analyzing mediating and moderating variables. Monographs of the Society for Research in Child Development, 71: 88-104.

[20] Doz, Y. 2011. Qualitative research for international business. Journal of International Business Studies, suppl. Special Issue: Qualitative Research in International 42 (5) 582-590.

[21] Dyer, J.H., Kale, P. \& Singh, J. H. 2001. . How to Make Strategic Alliances Work. MIT Sloan Management Review. 42. (4) 37-43.

[22] Dunning, J. H. \& Wymbs, C. 2003. The challenge of electronic markets for international business theory. Eds Cantwell, J. \& Narula, R. International Business and The Eclectic Paradigm. 219-251.

[23] Eisenhardt, K.M. (1989) 'Building theories from case study research', Academy of Management Review, 14: 532-550.

[24] Ellis, Paul, 2000. Social ties and foreign market entry, Journal of International Business Studies, 31(3): 443-469.

[25] Elsbach, K. \& Kramer. 2003. Assessing creativity in Hollywood pitch meetings: Evidence for a dual process model of creativity judgment. Academy of Management Journal, 46 (3), 283-302.

[26] Erramilli, K. 1996. Nationality and subsidiary ownership patterns in multinational corporations. Journal of International Business Studies. 27. 225-248.

[27] Finlay, W. \& Coverdill, J. E. 2000. Risk, opportunism and structural holes: How headhunters manage clients and earn fees. Work and Organizations. 27: 377-405.

[28] Folta, T. \& Ferrier, W. 2000. The effect of national culture on partner buyouts in cross-border biotechnology alliances. Journal of High Technology Management Research. 11 (2) 175-198.

[29] Gaddis, Blaine H. 2005. Training articulation of key causes, key resources, and key goals: Content-based training as an alternative to improving planning performance. The University of Oklahoma, 2005. Diss. 3162827.

[30] Gemser, G., Brand, M. J., and Sorge, Arndt. 2004. Exploring the internationalisation process of small businesses: A study of Dutch old and new economy firms, Management International Review, 44(2): 127-150.

[31] Gerring, J. 2007a. The mechanistic worldview: Thinking inside the box. British Journal of Political Science, 38 : 161-179.

[32] Gerring, J. 2007b. Case study research: Principles and practices. New York: Cambridge University Press.

[33] George, A. L., \& Bennett, A. 2004. Case studies and theory development in the social sciences. Cambridge, MA: MIT Press.

[34] Gibbert M, Ruigrok W, Wicki B. 2008. What passes as a rigorous case study? Strategic Management Journal. 29(13): $1465-1474$.

[35] Granovetter, M. 1973. The strength of weak ties. American Journal of Sociology. 78 (6). 1360-1380.

[36] Gulati, R. 1998. Alliances and networks. Strategic Management Journal. 19. 293-317. 
[37] Gulati, R. 1995. Social Structures and alliance formation patterns: A longitudinal analysis. Administrative Science Quarterly, 40 (4) 619-653.

[38] Gulati, R., Lavie, D. \& Singh, H. 2009. The nature of partnering experience and the gains from alliances Strategic Management Journal 30. (11) 1213.

[39] Harrigan, K. 1985. Strategies for joint ventures. Lexington. MA. Lexington Books.

[40] Hall, S.. 2006. What counts? Exploring the production of quantitative financial narratives in London's corporate finance industry. Journal of Economic Geography 6. (5) 661.

[41] Hennart, J. 1988 A Transaction Costs Theory of Equity Joint Ventures. Strategic Management Journal 9. (4) 361.

[42] Inkpen, A. \& Beamish, P. 1997. Knowledge, bargaining power and international joint venture instability. Academy of Management Review, 22: 177-202.

[43] Jick, T. 1979. Mixing qualitative and quantitative data. Administrative Science Quarterly, 24 (4) 602-612.

[44] Kale, P., Dyner, J., \& Singh, H. 2002. Alliance capability, stock market response, and long-term alliance success; the role of the alliance function. Strategic Management Journal. 23 747-767.

[45] Kale, P. \& Singh, H.. 2007. Building firm capabilities through learning: the role of the alliance learning process in alliance capability and firm-level alliance success. Strategic Management Journal 28. (10) 981.

[46] Kilduff, M. \& Tsai, W. 2005. Social Networks and Organizations. Sage Publications. Thousand Oaks.

[47] Krackhardt, D. 1999. The ties that torture: Simmelian tie analysis in organizations. Research in Sociology of Organizations. 16. 183-210.

[48] Kuemmerle, W. 2004. Cases in International Entrepreneurship. McGraw-Hill/Irwin.

[49] Larsson, R. \& Lowendahl, B. 1996. August. The qualitative side of management research: a meta-analysis of espoused and used case study methodologies. Paper presented at the Academy of Management Annual Meeting, Cincinnati, OH.

[50] Lawson, T. 2003. Reorienting economics. London: Routledge.

[51] Lee, T., Mitchell, T., \& Sablynski, C. 1999. Qualitative research in organizational and vocational psychology, 1979-1999. Journal of Vocational Behavior. 55, 161-187.

[52] Leonidou, L. 2004. An analysis of the behaviors hindering small business export development. Journal of Small Business Management. 42 (3) 279-302.

[53] Mahoney, J., \& Goertz, G. 2006. A tale of two cultures: Contrasting qualitative and quantitative research. Political Analysis, 14 (3): 227-249.

[54] Obstfeld, D. 2005. Social Networks, the tertius iungens orientation, and involvement in innovations. Administrative Science Quarterly. 50. 100-130.

[55] Oviatt, B. \& McDougall, P. 1994. Toward a theory of international new ventures. Journal of International Business Studies. 9 (6), 469-487.
[56] Pentland, B. 1999. Building theory with narrative: from description to explanation. Academy of Management Review. 24 (4) 711-725.

[57] Pettigrew, A. 1990. Longitudinal field research on change: Theory and practice. Organization Science. 1 (3). 267-292.

[58] Pollock, T.G., Porac, J. F., \& Wade, J. B. 2004. Constructing deal networks: Brokers as network "architects" in the U.S. IPO market and other examples. Academy of Management Review. 29: 50-72.

[59] Poole, M., Van de Ven, A., Dooley, K., Holmes, M. 2000. Organizational Change and Innovation Changes. New York. Oxford University Press.

[60] Pratt, M. \& Rosa, J. 2003. Transforming work family conflict into commitment in network marketing organizations. Academy of Management Journal. 46 (4). 395-418.

[61] Reed, M. 1997. In praise of duality and dualism: Rethinking agency and structure in organizational analysis. Organization Studies. 18. 21-42.

[62] Reuer, Jeffrey J; Koza, Mitchell P. 2000. Asymmetric information and joint venture performance: Theory and evidence for domestic and international joint ventures. Strategic Management Journal $\quad 21.181$.

[63] Sayer, A. 1992. Method in social science: A realist approach. (2nd ed.) London: Routledge.

[64] Simmel, G. 1950. The Sociology of George Simmel. Trans. By K.H. Wolff. Glencoe, IL. Free Press.

[65] Simonin, Bernard L. 1997 The importance of collaborative know-how: An empirical test of the learning organization. Academy of Management Journal 40. (5) 1150-1174.

[66] Shee, Daniel Y. 2006. An Analytic Framework for Competence Set Expansion: Lessons Learned from an SME. Total Quality Management \& Business Excellence 17. 8 981.

[67] Shenkar, O. 2004. The role of cultural distance in international expansion.(Ed.) Trick, M. Global Corporate Evolution: Looking Inward/Looking Outward. Carnegie Bosch Institute. Pittsburgh, PA.

[68] Todeva, E., and Knoke, D. 2005 Strategic alliances and models of collaboration, Management Decision, 43(1): 123-145.

[69] Tsai, W. \& Ghoshal, S. 1998. Social capital and value creation: The role of intrafirm networks. Academy of Management Journal. 41: 464-476.

[70] Van de Ven, A. \& Huber, G. 1990. Longitudinal field research methods for studying processes of organizational change. Organization Science. 1 (3). 213-2119

[71] Van de Ven A. \& Poole, M. 1995, Explaining development and change in organizations, Academy of Management Review, 20 (3))

[72] Van Maanen, J. 1979. Reclaiming qualitative methods for organizational research: A preface. Administrative Science Quarterly. 24, pp. 520-526.

[73] Weber, Y., Shenkar, O. \& Raveh, A. 1996. National and corporate culture fit in mergers/acquisitions: An exploratory study. Management Science. 42 (8), 1215-1227. 
[74] Welch, Catherine; Piekkari, Rebecca; Plakoyiannaki, Emmanuella; Paavilainen-mäntymäki, Eriikka. 2011. Theorising from case studies: Towards a pluralist future for international business research Journal of International Business Studies, suppl. Special Issue: Qualitative Research in International. 42 (5) 740-762.

[75] Yin, R. K. 2003. Case study research: Design and Methods. Thousand Oaks, CA: Sage. 